\title{
Trends in Air Pollutant Concentrations and the Impact of Meteorology in Shandong Province, Coastal China, during 2013-2019
}

\author{
Na Zhao', Gang Wang ${ }^{2,3 *}$, Guohao Li $^{4,5}$, Jianlei Lang ${ }^{6 *}$ \\ ${ }^{1}$ Shanghai Key Laboratory of Atmospheric Particle Pollution and Prevention, Department of \\ Environmental Science and Engineering, Institute of Atmospheric Sciences, Fudan University, \\ Shanghai 200433, China \\ ${ }^{2}$ Shanghai Key Lab for Urban Ecological Processes and Eco-Restoration, East China Normal \\ University, Shanghai 200241, China \\ ${ }^{3}$ Department of Environmental and Safety Engineering, College of Chemical Engineering, China \\ University of Petroleum (East China), Qingdao 266580, China \\ ${ }^{4}$ Municipal Research Institute of Environmental Protection, Beijing 100037, China \\ ${ }^{5}$ Key Laboratory of Beijing on VOC Pollution Control Technology and Application of Urban \\ Atmosphere, Beijing 100037, China \\ ${ }^{6}$ Key Laboratory of Beijing on Regional Air Pollution Control, Beijing University of Technology, \\ Beijing 100124, China
}

\section{ABSTRACT}

Although weather conditions significantly affect air pollutant concentrations, few quantitative studies have been conducted on the effects of long-term and seasonal changes in meteorology on air quality. Hence, in this study, the trends in Shandong Province, China, for six criteria pollutants (viz., sulfur dioxide [ $\mathrm{SO}_{2}$ ], carbon monoxide [CO], particulate matter [PM] with an aerodynamic diameter of $<10 \mu \mathrm{m}\left[\mathrm{PM}_{10}\right], \mathrm{PM}$ with an aerodynamic diameter of $<2.5 \mu \mathrm{m}\left[\mathrm{PM}_{2.5}\right]$, nitrogen dioxide $\left[\mathrm{NO}_{2}\right]$, and ozone $\left[\mathrm{O}_{3}\right]$ ) were analyzed for the period of 2013-2019, when overall emissions of air pollutants decreased, and the Weather Research and Forecasting model coupled with Chemistry (WRF/Chem) was applied to evaluate the role of inter-annual and seasonal meteorological changes. Five of the six criteria pollutants exhibited a sharp drop in concentration until 2017 and a gradual decline afterward, with the maximum and minimum annual values occurring during winter and summer, respectively. In contrast, the level of $\mathrm{O}_{3}$ rose between 2013 and 2019 and displayed the opposite seasonal trend. Also, the diurnal concentrations of the first five criteria pollutants showed a typical bimodal distribution, whereas those of the $\mathrm{O}_{3}$ showed a typical unimodal distribution. Furthermore, a trimodal distribution was observed for the ratios between the diurnal $\mathrm{PM}_{2.5}$ and $\mathrm{PM}_{10}$ concentrations. Using 2013 as the baseline, the inter-annual meteorological changes accounted for only $3.4-18.6 \%$ of the decrease in the five criteria pollutants - with little effect on the $\mathrm{O}_{3}$ - between 2015 and 2019, indicating that emission control measures drove the long-term improvement in air quality during these years. However, seasonal meteorological factors, which favored diffusion during summer and winter but accumulation during spring and autumn, played a larger role in the short term for all six species, especially during winter, when they reduced concentrations (excluding those of $\mathrm{SO}_{2}$ in 2019 and $\mathrm{O}_{3}$ altogether) by $6.5-31.0 \%$.

Keywords: Air pollution, Seasonal variation, Diurnal variation, WRF/Chem, Meteorological condition

This is an open access article distributed under the terms of the Creative Commons Attribution License (CC BY 4.0), which permits unrestricted use, distribution, and reproduction in any medium, provided the original author and source are cited.

\section{INTRODUCTION}

The air quality in China has been significantly improved since the implementation of the Action 
Plan for Prevention and Control of Air Pollution in September 2013. As one of the most developed and populous provinces of China, the Shandong also issued the Prevention and Control Planning of Air Pollution (abbreviated as "Air Pollution Planning") to mitigate air pollution in July 2013, which included controlling key industries (such as power plants and the steel industry), fugitive dust pollution (such as construction dust and straw burning), and vehicle emissions (such as strengthening emission standard and promoting the use of clean fuels).

The improvement of air quality benefits from the emission reduction of pollution sources over the past few years (Liu et al., 2015; Li et al., 2019; Wang et al., 2020b). Zheng et al. (2018) reported that China's anthropogenic emissions decreased by $59 \%$ for sulfur dioxide $\left(\mathrm{SO}_{2}\right), 21 \%$ for nitrogen oxides $\left(\mathrm{NO}_{x}\right.$ ), $23 \%$ for carbon monoxide (CO), 36\% for $\mathrm{PM}_{10}$ (particulate matter with aerodynamic diameters less than $10 \mu \mathrm{m}$ ), and 33\% for $\mathrm{PM}_{2.5}$ (aerodynamic diameters less than $2.5 \mu \mathrm{m}$ ) during 2013-2017. The $\mathrm{NO}_{x}$ emissions over 48 Chinese cities increased by 52\% from 2005 to 2011 and decreased by 21\% from 2011 to 2015 (Liu et al., 2017). The total emissions of six major atmospheric pollutants $\left(\mathrm{PM}_{2.5}, \mathrm{PM}_{10}, \mathrm{SO}_{2}, \mathrm{NO}_{x}\right.$, volatile organic compounds (VOCs), and ammonia $\left(\mathrm{NH}_{3}\right)$ ) in Beijing have also followed a downward trend, decreased by $35 \%$ in 2015 compared to 2006 (Xue et al., 2019). Several studies have also focused on analyzing the trends in air pollutant concentrations (Shen et al., 2018; Wang et al., 2019b; Li et al., 2020a) and chemical composition of $\mathrm{PM}_{2.5}$ (Lang et al., 2017; Geng et al., 2019; Kong et al., 2020) in megacities and typical urban agglomerations in China. The annual average concentrations of particles and their chemical compositions (such as $\mathrm{SO}_{4}{ }^{2-}$, organic matter, $\mathrm{NH}_{4}{ }^{+}$) have exhibited a significant decreasing trend in 74 key cities and three major urban agglomerations (such as Beijing-Tianjin-Hebei, Pearl River Delta, and the Yangtze River Delta) in China during 2013-2017, while the elemental carbon concentration increased in the Pearl River Delta, Fenhe, and Weihe River Plain (Wang et al., 2019b). Among the three major regions, the largest reduction in $\mathrm{PM}_{2.5}$ and its chemical constituents was observed in BeijingTianjin-Hebei during 2013-2017 (Geng et al., 2019). Field studies on the trends of air pollutant concentrations in Shandong Province, the coastal region of China, have not yet been conducted.

The meteorological conditions also play a critical role in air quality (Zhai et al., 2019; Zhao et al., 2020). For example, severe air pollution events occurred in northern China during January 2020 , with the daily average concentration of $\mathrm{PM}_{2.5}$ exceeding $200 \mu \mathrm{g} \mathrm{m}^{-3}$, although the pollutant emissions decreased due to the Spring Festival holiday and coronavirus disease outbreak (Wang et al., 2020d; Zhang et al., 2020a). Several studies have explored the contribution of inter-annual meteorological changes to air pollutant concentration reductions (Hong et al., 2019; Vu et al., 2019; Xue et al., 2020; Zhang et al., 2020b). The decrease in the PM2.5 concentration due to emissions reduction increased annually from 2013-2017 in key regions of China, especially in 2016 and 2017 (Zhang et al., 2019b). Changes in meteorology have led to an increase in the maximum daily 8-h average $\mathrm{O}_{3}$ concentration over the central part of central-eastern China, while it decreased over the eastern part of the region in 2003-2015 (Sun et al., 2019). However, the contribution of meteorological conditions may be influenced by the local climate due to the complexity of meteorological changes. Zhang et al. (2019b) found that the meteorological factors played more important role in the decrease of $\mathrm{PM}_{2.5}$ in winter in the Beijing-Tianjin-Hebei and the Yangtze River Delta. Field studies on the impact of seasonal meteorological conditions on air quality have seldom been reported. Therefore, evaluating the contributions of inter-annual and seasonal meteorological changes to air pollutant concentration reductions should be further studied.

Shandong Province $\left(114.79-122.71^{\circ} \mathrm{E}, 34.38-38.40^{\circ} \mathrm{N}\right)$ is located in eastern China, and is surrounded by the Yellow and Bohai Seas on three sides. In this study, the seasonal and diurnal variations of six criteria pollutant (including $\mathrm{SO}_{2}, \mathrm{CO}, \mathrm{PM}_{10}, \mathrm{PM}_{2.5}, \mathrm{NO}_{2}$, and $\mathrm{O}_{3}$ ) concentrations from 2013 to 2019 in Shandong Province were analyzed. The contributions of the meteorological changes to the concentration reductions of six criteria pollutants were also evaluated, especially from the perspective of inter-annual and seasonal. The results are helpful in exploring the efficacy of control measures and policy making.

\section{METHODS}

\subsection{Data Source}

The hourly concentrations of six criteria pollutants at 74 monitoring stations covering 16 cities 
were obtained from the Department of Ecological Environment of Shandong Province. Note that the concentrations of $\mathrm{O}_{3}$ and $\mathrm{CO}$ were not released from January to September in 2013, excluding Jinan and Qingdao. Additionally, the meteorological conditions (ambient temperature [T], relative humidity [RH], precipitation [Pre], wind speed [WS], and wind direction [WD]) were obtained from the Meteorological Information Comprehensive Analysis and Process System (MICAPS) of the China Meteorological Administration. Fig. S1 illustrates the location of Shandong Province and the monitoring stations.

\subsection{WRF/Chem Modeling System}

In this study, the Weather Research and Forecasting model coupled with Chemistry (WRF/Chem) was applied to evaluate the contribution of meteorological changes to air pollutant concentration reductions in Shandong Province, which has been widely used for mesoscale simulation and has been proven to be reliable (Chen et al., 2017, 2018; Lv et al., 2020; Wang et al., 2020e; Xing et al., 2020). The initial and lateral meteorological boundary conditions for WRF/Chem were generated using the National Centers for Environmental Prediction (NCEP) Final Analysis (FNL) data, which were available at a $1 \times 1^{\circ}$ resolution and temporal resolution of $6 \mathrm{~h}$. A two-level nested-grid architecture was employed to implement the WRF/Chem modelling system (Fig. 1). Domain 1 covers most areas of north-eastern China with a grid resolution of $27 \times 27 \mathrm{~km}$, and Domain 2 covers Shandong Province and the surrounding regions with a $9 \times 9 \mathrm{~km}$ grid resolution.

The target simulation periods were January, April, July, and October from 2013 to 2019, representing winter, spring, summer, and autumn, respectively. The scenarios were run separately using the meteorological conditions of 2013, 2015, 2017, and 2019, while other configurations (such as the emission sources, physical schemes, and chemical schemes) for all simulations were the same. The 2016 emission inventory used for simulation was obtained and processed from the Multi-resolution Emission Inventory for China (MEIC; http://www.meicmodel.org/). Thus, the differences between the scenarios can illustrate the impact of meteorological changes.

\subsection{Model Evaluation}

To evaluate the modeling performance, the simulated meteorological parameters (e.g., temperature at $2 \mathrm{~m}\left[\mathrm{~T}_{2}\right]$, relative humidity at $2 \mathrm{~m}\left[\mathrm{RH}_{2}\right]$, wind speed at $10 \mathrm{~m}\left[\mathrm{WS}_{10}\right]$, and wind direction at $10 \mathrm{~m}\left[\mathrm{WD}_{10}\right]$ ) and the concentrations of six criteria pollutants from the lowest layer were compared with the observations. The correlative coefficient (R), normalized mean bias (NMB), and normalized mean error (NME) were analyzed according to the United States Environmental Protection Agency (EPA) model evaluation protocol (U.S. EPA, 2007).

In general, the agreement of meteorological parameters between simulated and observed data was good with $\mathrm{R}, \mathrm{NMB}$, and $\mathrm{NME}$ of $\mathrm{T}_{2}$ ranging from 0.5 to $0.9,-1.1 \%$ to $-0.2 \%$, and $10.8 \%$ to $41.3 \%$, respectively in different seasons in 2013-2019 (Table 1). The simulated $\mathrm{RH}_{2}$ were also compared with the observed data with $\mathrm{R}$ ranging from 0.5 to 0.8 , and the $\mathrm{NMB}$ and $\mathrm{NME}$ ranging from $-17.9 \%$ to $34.2 \%$ and $11.8-38.8 \%$, respectively. The $R, N M B$, and NME of WS 10 ranged from

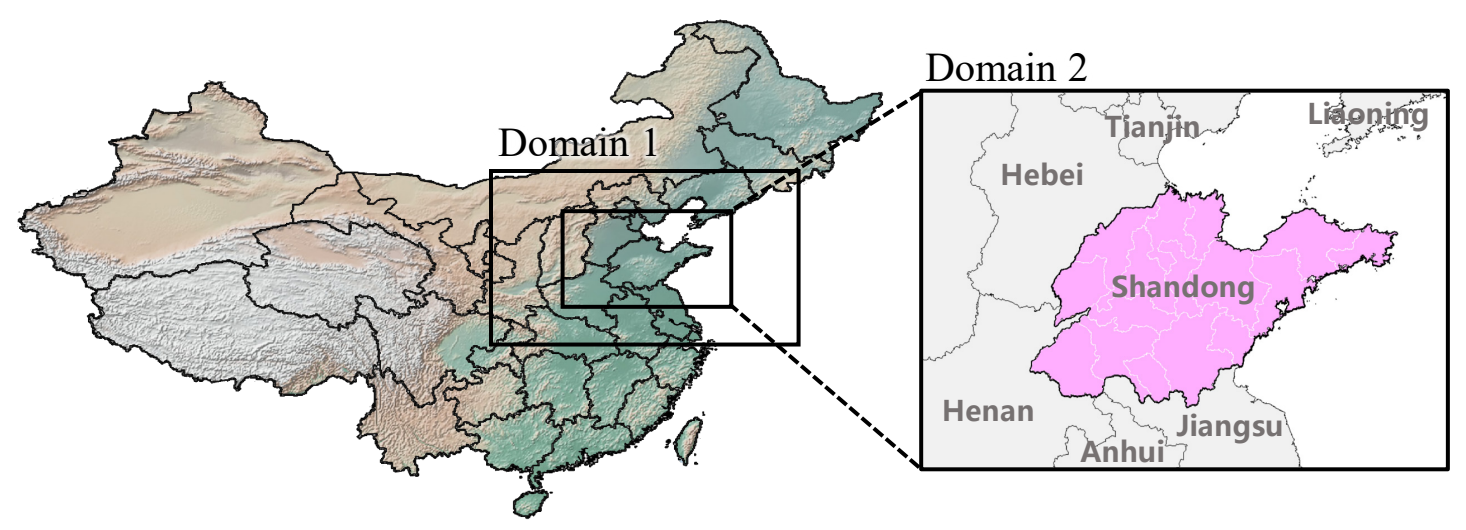

Fig. 1. Design of two-level modeling domains. 
Table 1. Comparisons of meteorological parameters between simulated and observed data.

\begin{tabular}{|c|c|c|c|c|c|c|c|c|c|c|}
\hline \multirow{2}{*}{ Year } & \multirow{2}{*}{ Season } & \multicolumn{3}{|c|}{$\mathrm{T}_{2}\left({ }^{\circ} \mathrm{C}\right)$} & \multicolumn{3}{|c|}{$\mathrm{RH}_{2}(\%)$} & \multicolumn{3}{|c|}{$W S_{10}\left(\mathrm{~m} \mathrm{~s}^{-1}\right)$} \\
\hline & & $\mathrm{R}$ & NMB (\%) & NME (\%) & $\mathrm{R}$ & NMB (\%) & NME (\%) & $\mathrm{R}$ & NMB (\%) & NME (\%) \\
\hline \multirow[t]{4}{*}{2013} & Spring & 0.9 & -0.4 & 26.8 & 0.8 & -5.4 & 38.8 & 0.7 & -27.5 & 13.8 \\
\hline & Summer & 0.8 & -0.3 & 15.4 & 0.5 & -13.7 & 22.9 & 0.6 & -15.3 & 35.7 \\
\hline & Autumn & 0.9 & -0.6 & 19.6 & 0.5 & 8.6 & 29.3 & 0.5 & -13 & 22.6 \\
\hline & Winter & 0.8 & -0.7 & 40.5 & 0.7 & 9.7 & 35.4 & 0.6 & -10.5 & 18.9 \\
\hline \multirow[t]{4}{*}{2015} & Spring & 0.8 & -0.6 & 24.4 & 0.8 & -11.9 & 23.6 & 0.8 & -20.8 & 20.4 \\
\hline & Summer & 0.7 & -0.5 & 11.5 & 0.5 & 34.2 & 33.3 & 0.5 & -11.9 & 30.9 \\
\hline & Autumn & 0.8 & -0.4 & 38.5 & 0.5 & 24.7 & 38.1 & 0.5 & -19.5 & 25.7 \\
\hline & Winter & 0.8 & -0.5 & 18.1 & 0.8 & 12.9 & 30.5 & 0.8 & -14.2 & 16.4 \\
\hline \multirow[t]{4}{*}{2017} & Spring & 0.5 & -0.6 & 26.3 & 0.6 & -9.6 & 37.9 & 0.5 & -22.1 & 24.1 \\
\hline & Summer & 0.7 & -0.4 & 12.8 & 0.7 & 8.4 & 11.8 & 0.7 & -12.4 & 31.1 \\
\hline & Autumn & 0.7 & -0.2 & 22 & 0.7 & -8.8 & 23.6 & 0.7 & -15.5 & 14.2 \\
\hline & Winter & 0.8 & -0.3 & 41.3 & 0.7 & -9.9 & 27.5 & 0.7 & -13.3 & 16.9 \\
\hline \multirow[t]{4}{*}{2019} & Spring & 0.9 & -0.7 & 16.5 & 0.8 & -8.6 & 26.5 & 0.8 & -17.6 & 23.3 \\
\hline & Summer & 0.8 & -0.6 & 10.8 & 0.7 & 22.4 & 17.7 & 0.7 & -14.7 & 35.7 \\
\hline & Autumn & 0.9 & -0.8 & 17.6 & 0.8 & -17.9 & 22.8 & 0.8 & -16.2 & 22.6 \\
\hline & Winter & 0.8 & -1.1 & 36.6 & 0.7 & -17.3 & 27 & 0.8 & -9.8 & 20.4 \\
\hline
\end{tabular}

$\mathrm{T}_{2}$ : temperature at $2 \mathrm{~m} ; \mathrm{RH}_{2}$ : relative humidity at $2 \mathrm{~m} ; \mathrm{WS}_{10}$ : wind speed at $10 \mathrm{~m}$; R: correlation coefficient; NMB: normalized mean bias; NME: normalized mean errors. The R, NMB, and NME were calculated based on the simulated and observed data. The simulated data were extracted from grids covering 16 cities in Shandong Province in 2013-2019. The observed data at 16 monitoring stations covering 16 cities were obtained from the Meteorological Information Comprehensive Analysis and Process system (MICAPS) of the China Meteorological Administration. The location of the meteorology monitoring stations can be found in Fig. S1.

0.5 to $0.8,-27.5 \%$ to $-9.8 \%$, and $13.8 \%$ to $35.7 \%$, respectively. For $\mathrm{WD}_{10}$, the mean bias (MB) and gross error (GE) were analyzed according to other studies (Hu et al., 2016; Emery et al., 2017; Wang et al., 2019a) and compared with the benchmarks suggested by Emery et al. (2001) (Table S1). MB values of $W D_{10}$ were within the benchmark of $\leq \pm 10$ for $1,3,1$, and 1 season in 2013, 2015, 2017, and 2019, respectively.

The comparison of observed and simulated criteria pollutant concentrations showed that the model reproduced the variations of concentrations (Table 2). The R, NMB, and NME of air pollutants ranged from 0.5 to $0.7,-18.4 \%$ to $15.9 \%$, and $11.5 \%$ to $39.7 \%$, respectively. This might be explained by the uncertainties inherent in emission inventories and the unavoidable deficiencies of meteorological and air quality models. By keeping these uncertainties in mind, the modeling performance of the WRF/Chem for simulating temporal and spatial distribution of meteorology and air pollutant concentrations in Shandong Province was reasonably good for the modeled period (Wang et al., 2017a, b; Chen et al., 2018).

\section{RESULTS AND DISCUSSION}

\subsection{Trends in the Air Pollutant Concentrations}

Concentrations of five criteria pollutants (exclude $\mathrm{O}_{3}$ ) decreased in Shandong Province from 2013-2019 (Fig. 2). The annual average concentrations of $\mathrm{SO}_{2}, \mathrm{NO}_{2}, \mathrm{O}_{3}, \mathrm{CO}, \mathrm{PM}_{10}$, and $\mathrm{PM}_{2.5}$ in 2013 were $69.6 \pm 26.9 \mu \mathrm{g} \mathrm{m}^{-3}, 48.0 \pm 9.5 \mu \mathrm{g} \mathrm{m}^{-3}, 43.2 \pm 15.4 \mu \mathrm{g} \mathrm{m}^{-3}, 1.7 \pm 0.6 \mathrm{mg} \mathrm{m}^{-3}, 161.4 \pm$ $43.0 \mu \mathrm{g} \mathrm{m}^{-3}$, and $96.5 \pm 27.8 \mu \mathrm{g} \mathrm{m}^{-3}$, respectively. The $\mathrm{SO}_{2}, \mathrm{NO}_{2}, \mathrm{PM}_{10}$, and $\mathrm{PM}_{2.5}$ concentrations were 1.2-2.8 times higher than the annual secondary guideline value (GB3095-2012). However, no annual standards are proposed for $\mathrm{CO}$ and $\mathrm{O}_{3}$ in China. The secondary guideline values for $\mathrm{CO}$ and $\mathrm{O}_{3}$ in this study are the 24-h and 1-h average concentration standards, and the $\mathrm{CO}$ and $\mathrm{O}_{3}$ concentrations met this standard in 2013. Six years after the implementation of Air Pollution Planning, this drove synergistic co-reductions in the $\mathrm{SO}_{2}, \mathrm{NO}_{2}, \mathrm{CO}, \mathrm{PM}_{10}$, and $\mathrm{PM}_{2.5}$ concentrations in 2019 , with decreases of $80.1 \%, 26.8 \%, 54.5 \%, 39.2 \%$, and $46.2 \%$ from the values in 2013 , respectively, while the increasing trend of the $\mathrm{O}_{3}$ concentration has not been sufficiently restricted. 
Table 2. Comparisons of air pollutants between simulated and observed data.

\begin{tabular}{|c|c|c|c|c|c|}
\hline Pollutant & Parameter & Spring & Summer & Autumn & Winter \\
\hline \multirow{3}{*}{$\mathrm{PM}_{10}$} & $\mathrm{R}$ & 0.6 & 0.7 & 0.7 & 0.6 \\
\hline & NMB (\%) & -6.8 & 5.9 & -11.3 & -18.4 \\
\hline & NME (\%) & 35.4 & 28.9 & 15.9 & 39.7 \\
\hline \multirow[t]{3}{*}{$\mathrm{PM}_{2.5}$} & $\mathrm{R}$ & 0.7 & 0.7 & 0.6 & 0.6 \\
\hline & NMB (\%) & -12.5 & 6.5 & -10.2 & -10.6 \\
\hline & NME (\%) & 20.5 & 15.8 & 30.5 & 38.4 \\
\hline \multirow[t]{3}{*}{$\mathrm{SO}_{2}$} & $\mathrm{R}$ & 0.6 & 0.7 & 0.6 & 0.6 \\
\hline & NMB (\%) & -9.8 & -14.6 & 6.8 & 5.6 \\
\hline & NME (\%) & 22.9 & 31.4 & 35.4 & 28.6 \\
\hline \multirow[t]{3}{*}{$\mathrm{NO}_{2}$} & $\mathrm{R}$ & 0.6 & 0.5 & 0.6 & 0.6 \\
\hline & NMB (\%) & 5.1 & 6.8 & -8.4 & -2.6 \\
\hline & NME (\%) & 26.4 & 20.6 & 21.4 & 32.4 \\
\hline \multirow[t]{3}{*}{$\mathrm{O}_{3}$} & $\mathrm{R}$ & 0.5 & 0.5 & 0.5 & 0.6 \\
\hline & NMB (\%) & 7.9 & 15.9 & 12.8 & -8.9 \\
\hline & NME (\%) & 23.6 & 33.6 & 30.5 & 18.4 \\
\hline \multirow[t]{3}{*}{$\mathrm{CO}$} & $\mathrm{R}$ & 0.7 & 0.6 & 0.6 & 0.6 \\
\hline & NMB (\%) & -2.5 & 5.2 & -3.8 & 6.7 \\
\hline & NME (\%) & 13.4 & 18.9 & 11.5 & 22.1 \\
\hline
\end{tabular}

The simulated data were extracted from grids covering 16 cities in Shandong Province in 2017. The observed data at 74 monitoring stations covering 16 cities in 2017 were obtained from the Department of Ecological Environment of Shandong Province. The location of the air quality monitoring stations can be found in Fig. S1.

The notable improvements in five criteria pollutants' concentrations reflect the combined effects of various emission-reduction measures that have been implemented over the past few years, such as adjusting the energy structure, industrial restructuring, upgrading emission control technologies, and controlling pollution from key industries. For example, Shandong Province emits the most air pollutants from the Chinese power industry due to its high coal consumption rate and dense distribution of coal-fired plants (Xiong et al., 2016). The CO, $\mathrm{PM}_{10}, \mathrm{PM}_{2.5}, \mathrm{SO}_{2}$, and $\mathrm{NO}_{x}$ emissions from power plants in Shandong Province accounted for $10-11 \%$ of the total emissions in China (Tong et al., 2018). China implemented an ultra-low-emission standard for coal-fired power plants in 2014 (MEE, 2018), and the installed capacity of ultra-low-emission coal units increased from zero in 2013 to 0.89 billion KW in 2019, accounting for $86 \%$ of the installed capacity of coal-fired units (MEE, 2020). This is considered as a significant achievement in air pollution control in China; therefore, the government is applying ultra-low-emission standards in other industries (Wang et al., 2020a). Note that the high air pollutant concentrations in 2013 was also due to the extremely poor ventilation conditions, which might be linked to Arctic Ocean ice loss in the preceding autumn and extensive boreal snowfall in the earlier winter (Zou et al., 2017).

The various $\mathrm{SO}_{2}$ emission reduction measures were most effective in 2013-2019, with a higher declining rate $(\sim 80 \%)$ than that of other pollutants (<55\%) (Fig. 2). Data from the National Bureau of Statistics showed that the $\mathrm{SO}_{2}$ emission in Shandong Province decreased by $55 \%$ during this period, while the emissions of $\mathrm{NO}_{2}$ and total suspended particles only decreased by $30 \%$ and $21 \%$, respectively (http://www.stats.gov.cn/tjsj/ndsj/). Owing to these measures, the number of clean days in Shandong Province exhibited an increasing trend, while the number of polluted days showed a decreasing trend (Fig. 3). Heavily polluted days have been almost eliminated, decreasing from 40 d in 2013 to 8 d in 2017 and 2019. The air pollution improvement objectives set in Air Pollution Planning were achieved in 2019 (DEE, 2018).

Despite the continuous improvement in the air quality of Shandong, the rate of the decrease in the concentrations of $\mathrm{PM}_{2.5}$ and $\mathrm{PM}_{10}$ slowed in the late stage of Air Pollution Planning due to an increase in the difficulty of pollution control due to the cost of treatment and development of control technologies. Therefore, technological improvement is vital for pollutant removal and improving air quality. The $\mathrm{PM}_{2.5}$ and $\mathrm{PM}_{10}$ concentrations decreased sharply in 2015 and 2017, with reductions ranging from $18.2 \%$ to $24.8 \%$ from the concentrations in 2013 , while the reduction rates decreased to $8.8-9.0 \%$ during $2017-2019$ (Fig. 2). 


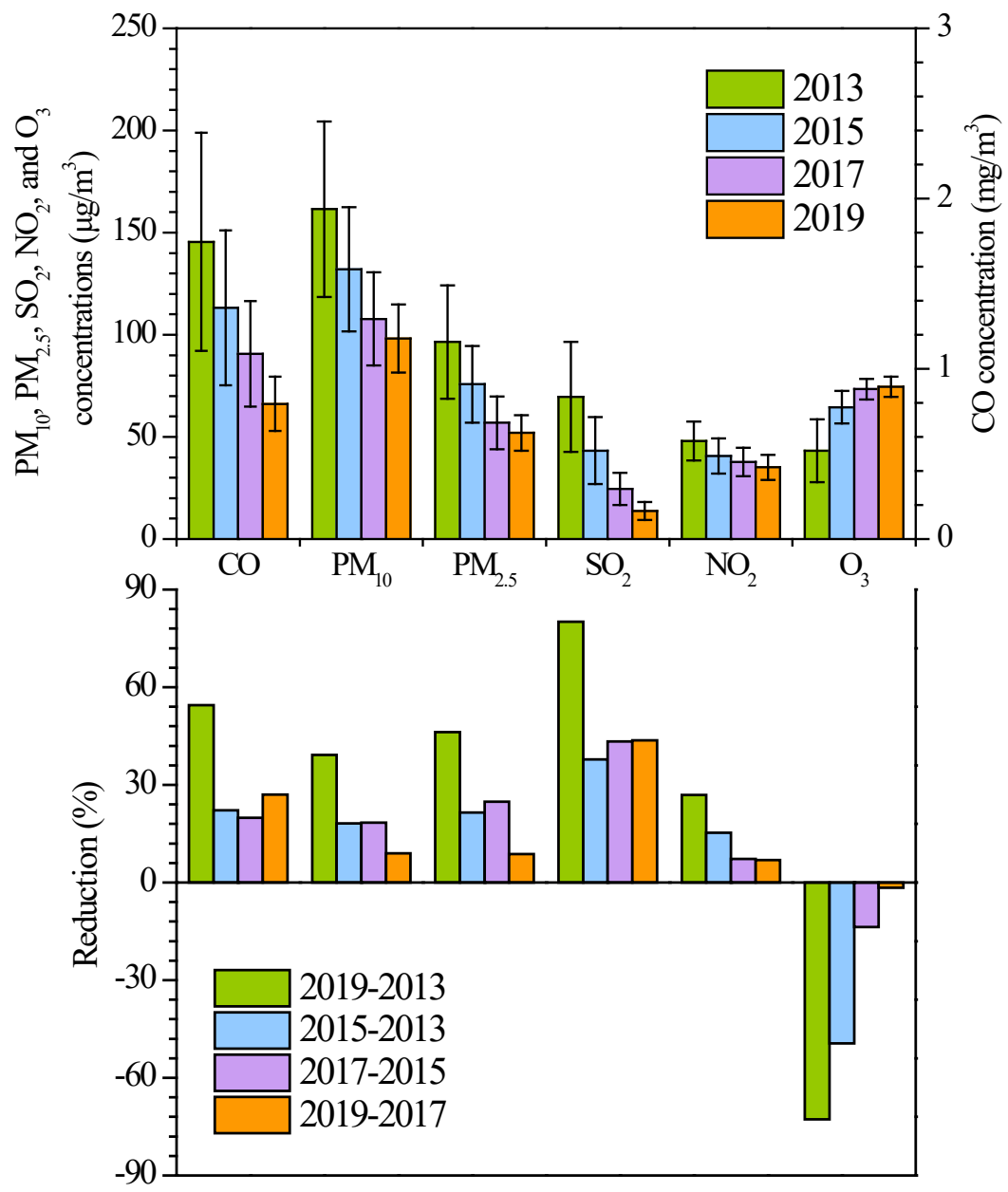

Fig. 2. Annual average concentrations and reductions of air pollutants in Shandong Province in 2013-2019. The concentrations are calculated based on the monitoring stations covering 16 cities of Shandong Province. 2019-2013 refers to lower ratios of air pollutant concentrations in 2019 than with that in 2013, and negative values indicate an increase in the concentrations.

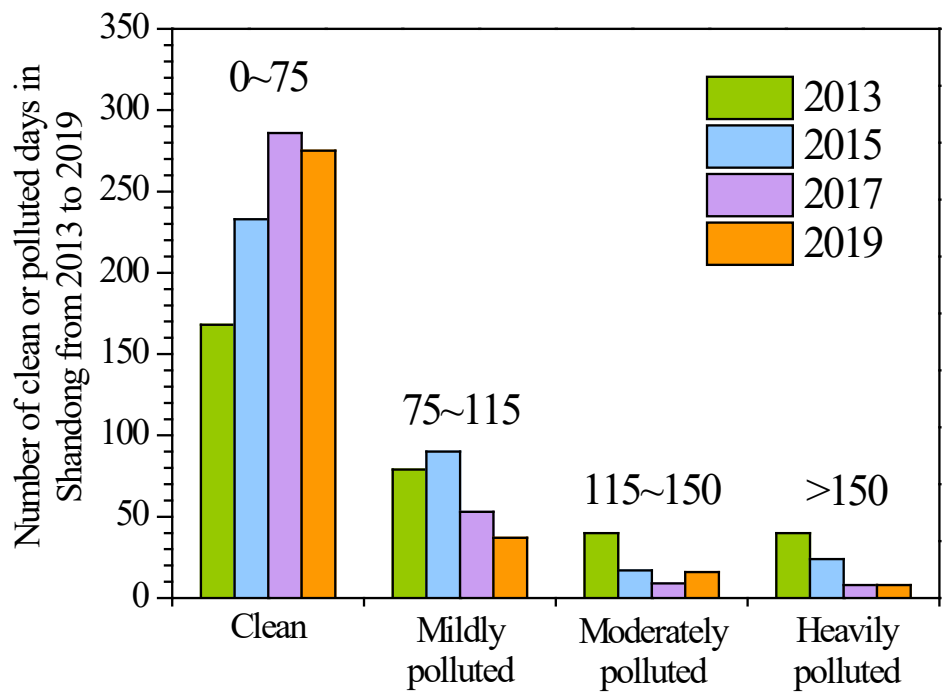

Fig. 3. Number of clean or polluted days in Shandong Province from 2013-2019. Days are divided into four categories based on the daily average $\mathrm{PM}_{2.5}$ concentrations covering 16 cities of Shandong Province according to the Technical Regulation on Ambient Air Quality Index (on trial; HJ633-2012). The values above columns are the guideline values for $\mathrm{PM}_{2.5}$ concentrations in each category. 
However, particle control over Shandong Province still faces a great challenge as the annual average particle concentrations in 2019 still exceeded the annual secondary guideline value (GB3095-2012). The particles were dominated by $\mathrm{PM}_{2.5}$, although the $\mathrm{PM}_{2.5} / \mathrm{PM}_{10}$ ratios decreased from $60 \%$ in 2013 to $53 \%$ in 2019. The decrease in the $\mathrm{PM}_{2.5} / \mathrm{PM}_{10}$ ratios ( 7\%) of Shandong Province was higher than that in other key regions (such as Beijing-Tianjin-Hebei and the Pearl River Delta), with a reduction of 2-3\% (Wang et al., 2019b), indicating that the stringent measures implemented for reducing particle emissions in Shandong Province are significant and effective. More measures should be implemented to reduce the emissions of particles and their gaseous precursors to mitigate particle pollution in Shandong Province, as particles can consist of various primary and secondary components (such as organic carbon, elemental carbon, sulfate, nitrate, and ammonium) (Wang et al., 2017a; Zhang et al., 2020b).

The $\mathrm{O}_{3}$ concentration increased by $72.7 \%$ in 2019 compared with that of 2013 , although the $\mathrm{NO}_{2}$ decreased by $26.8 \%$ (Fig. 2). $\mathrm{O}_{3}$ is a major atmospheric oxidant and is formed by the photochemical oxidation of hydrocarbons, $\mathrm{CO}$, and $\mathrm{NO}_{x}$ under solar radiation (Sun et al., 2019). It is more difficult to control $\mathrm{O}_{3}$ than other pollutants, as it is a secondary pollutant with a nonlinear relationship with its precursors (Tie et al., 2013). Studies on the $\mathrm{O}_{3}$ formation mechanism demonstrated that the sensitivity of $\mathrm{O}_{3}$ to precursors differs between different regions or under different pollution conditions (Jeon et al., 2014; Qiu, 2017; Fang et al., 2020; Yu et al., 2020). In this study, a negative exponential correlation was observed between the daily average concentrations of $\mathrm{NO}_{2}$ and $\mathrm{O}_{3}$ in 2013-2019 (Fig. 4). Control measures aimed at $\mathrm{NO}_{x}$ alone are insufficient to mitigate $\mathrm{O}_{3}$ pollution, and synergistic control with a desirable $\mathrm{NO}_{x} / \mathrm{VOC}$ reduction ratio is required for $\mathrm{O}_{3}$ reduction, as an inappropriate ratio is most likely responsible to be responsible for the increase in $\mathrm{O}_{3}$ (Yang et al., 2019; Wang et al., 2020c).

\subsection{Seasonal Variation}

The five criteria pollutants' concentrations exhibited clear seasonal variation characteristics, with the highest pollution occurring in winter and best air quality occurring in summer during 2013-2019, excluding $\mathrm{O}_{3}$ (Figs. 5 and S1). The seasonal variations can be attributed to the climate and human activities. A stable atmospheric vertical structure weakens the turbulent atmospheric exchange and hinders the diffusion and dilution of air pollutants in the vertical direction, which is favorable for the accumulation of pollutants in a local area with low wind speed during winter (Zhang et al., 2013; Shen et al., 2018). Chow et al. (1993) also found that the elevated particles (e.g., carbonaceous aerosol) could result from increased vegetative burning (i.e., fireplace and woodstove) during winter. Motor-vehicle-related primary contributions to organic carbon and elemental carbon could also be larger owing to cold starts and restricted atmospheric mixing.

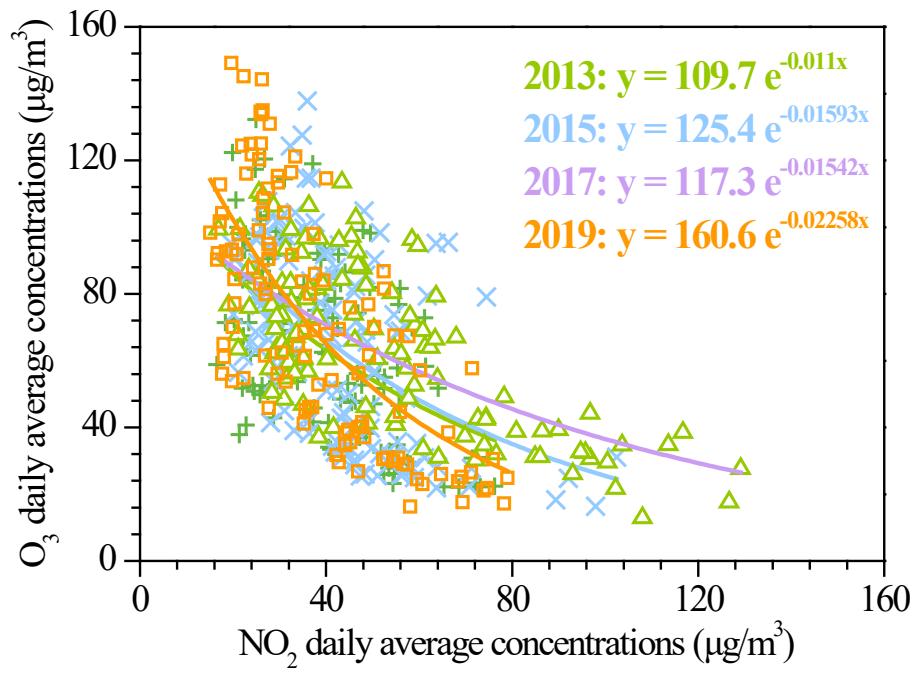

Fig. 4. Correlation between the daily average $\mathrm{O}_{3}$ and $\mathrm{NO}_{2}$ concentrations in Shandong Province in 2013-2019. The concentrations used in this figure are from January, April, July, and October in 2013-2019 covering 16 cities. 


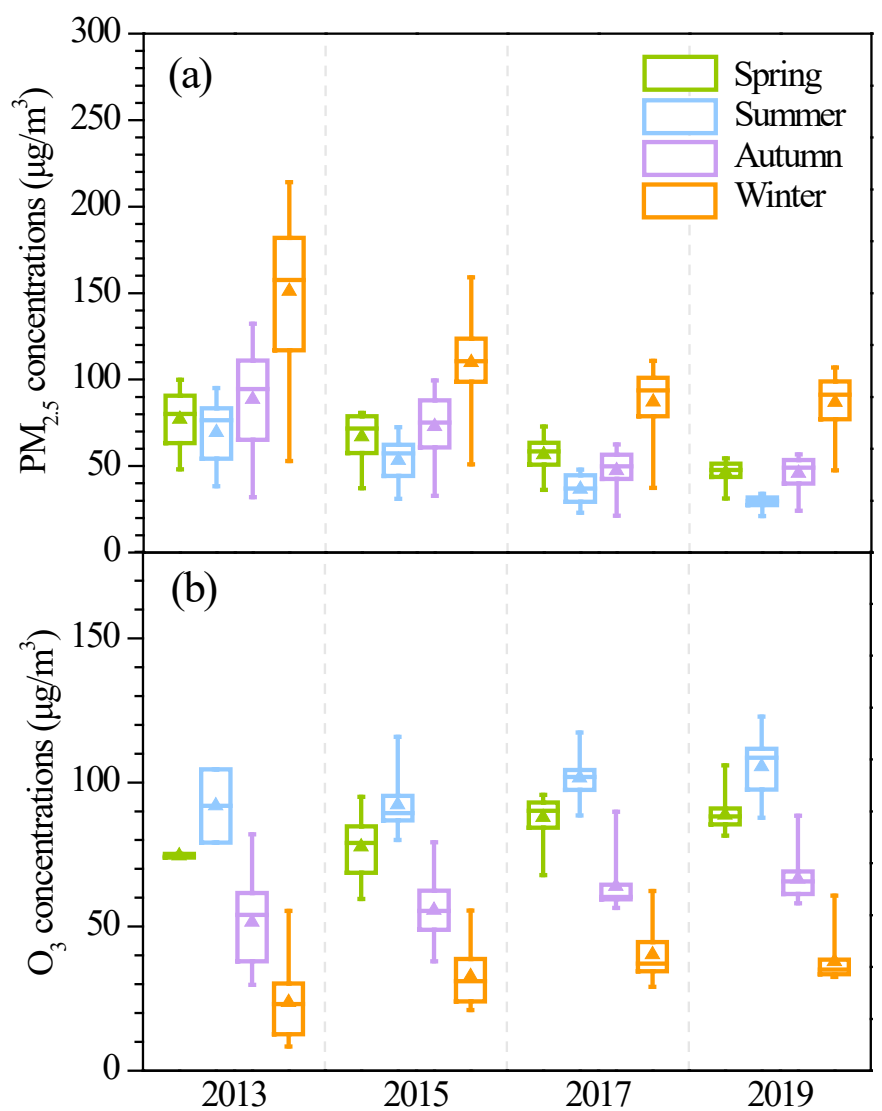

Fig. 5. Seasonal variations in the (a) $\mathrm{PM}_{2.5}$ and (b) $\mathrm{O}_{3}$ concentrations of Shandong Province during 2013-2019. The variations in the $\mathrm{CO}, \mathrm{PM}_{10}, \mathrm{SO}_{2}$, and $\mathrm{NO}_{2}$ concentrations are presented in Fig. S2. The concentrations are calculated based on the monitoring stations covering 16 cities of Shandong Province. Spring: March-May; summer: June-August; autumn: September-November; winter: December-February. The box plots refer to the $\max , 75^{\text {th }}, 50^{\text {th }}, 25^{\text {th }}$, and min percentiles of the corresponding dataset, and the triangles indicate the mean values.

The time required for the cold start of motor vehicles also increased due to the low $\mathrm{T}$ in winter $\left(0.5-2.6^{\circ} \mathrm{C}\right)$, facilitating the conversion of semi-volatile substances to particles and increasing exhaust emissions (Chow et al., 1993). During monsoon seasons, abundant Pre ranging 1312$4696 \mathrm{~mm}$ in Shandong Province during 2013-2019 along with high winds from the sea can alleviate air pollution compared with other seasons ranging 94-856 mm (Wang et al., 2015). Regarding human activities, fire points were observed based on satellites in Shandong Province in winter (http://satsee.radi.ac.cn:8080/index.html), indicating the increased combustion (coal and biomass) for heating resulted in the highest air pollutant concentrations in winter (Li et al., 2020b; Zhou et al., 2020). All of these factors resulted in great fluctuations in the five criteria pollutants' concentrations during the four seasons.

The decreases in $\mathrm{SO}_{2}$ and $\mathrm{CO}$ concentrations were more prominent in autumn and winter during 2013-2019, while in summer for $\mathrm{PM}_{2.5}, \mathrm{PM}_{10}$, and $\mathrm{NO}_{2}$ (Table S2). As one of the main sources of $\mathrm{SO}_{2}$ and $\mathrm{CO}$ in autumn and winter, coal consumption has been reduced by over 30 million tons, and seven cities in Shandong Province replaced coal power with gas and electricity over the last few years. Furthermore, fireworks and firecrackers are important contributors to air pollution during the Spring Festival, and the impact is more severe when stable atmospheric conditions occur during winter. Fireworks and firecrackers have been forbidden in some cities to reduce the air pollutant emissions in Shandong Province, leading to a significant decrease in the pollutant concentrations.

The $\mathrm{O}_{3}$ concentrations in different seasons followed the order of winter $<$ autumn $<$ spring $<$ summer in 2013-2019 (Fig. 5). T and solar radiation are important factors affecting $\mathrm{O}_{3}$ formation by photochemical reactions (Tang et al., 2009). Taking Jinan as an example, a strong positive 
correlation between the $\mathrm{T}$ and $\mathrm{O}_{3}$ concentrations was observed during the summers of 20132019 with the correlative coefficient of 0.62 (Fig. 6(a)). The high T during these periods led to strong solar radiation and accelerated the photochemical reaction rate. Furthermore, as a major precursor, the evaporation of VOCs emissions from vegetation and painting increases under higher T (Squires et al., 2020). Sun et al. (2019) reported that increased levels of anthropogenic non-methane VOCs are the main cause of the increases in $\mathrm{O}_{3}$ over the eastern part of centraleastern China. The $\mathrm{O}_{3}$ concentration exhibited a negative correlation with the $\mathrm{RH}$ in the summer with the correlative coefficient of -0.68 (Fig. $6(\mathrm{~b})$ ). High RH (such as summer Pre) has a scavenging effect on the precursors of $\mathrm{O}_{3}$, affects solar radiation, and indirectly inhibits the formation of $\mathrm{O}_{3}$. Therefore, high $\mathrm{T}$, low $\mathrm{RH}$, and low wind are favorable for the formation of $\mathrm{O}_{3}$ near the ground.

\subsection{Diurnal Variation}

The diurnal variations in five criteria pollutants' concentrations exhibited a typical bimodal distribution, except for $\mathrm{O}_{3}$, with the maximum concentrations occurring from 08:00 to 10:00 and 20:00 to $00: 00$, and minimum concentrations occurring from 0:00 to 07:00 and 14:00 to 18:00 in 2013-2019 (Figs. 7 and S2), which was generally consistent with those in other megacities and urban agglomerations (Zhou et al., 2015; Shen et al., 2018; Kuerban et al., 2020). This variation was affected by the diurnal emissions and meteorological conditions. There are two traffic rush hours in the morning and evening, and the morning peak of the air pollutant concentrations was closely related to the increased vehicle emissions and road dust during the first traffic rush hour. Air pollutants were accumulated after the second rush hour in the evening under a decreased boundary layer height, which suppressed the diffusion of pollutants (Zhang et al., 2014; Xie et al., 2019). The lower values in the afternoon were attributed to the increased boundary layer height, which was conducive to the diffusion of air pollutants.

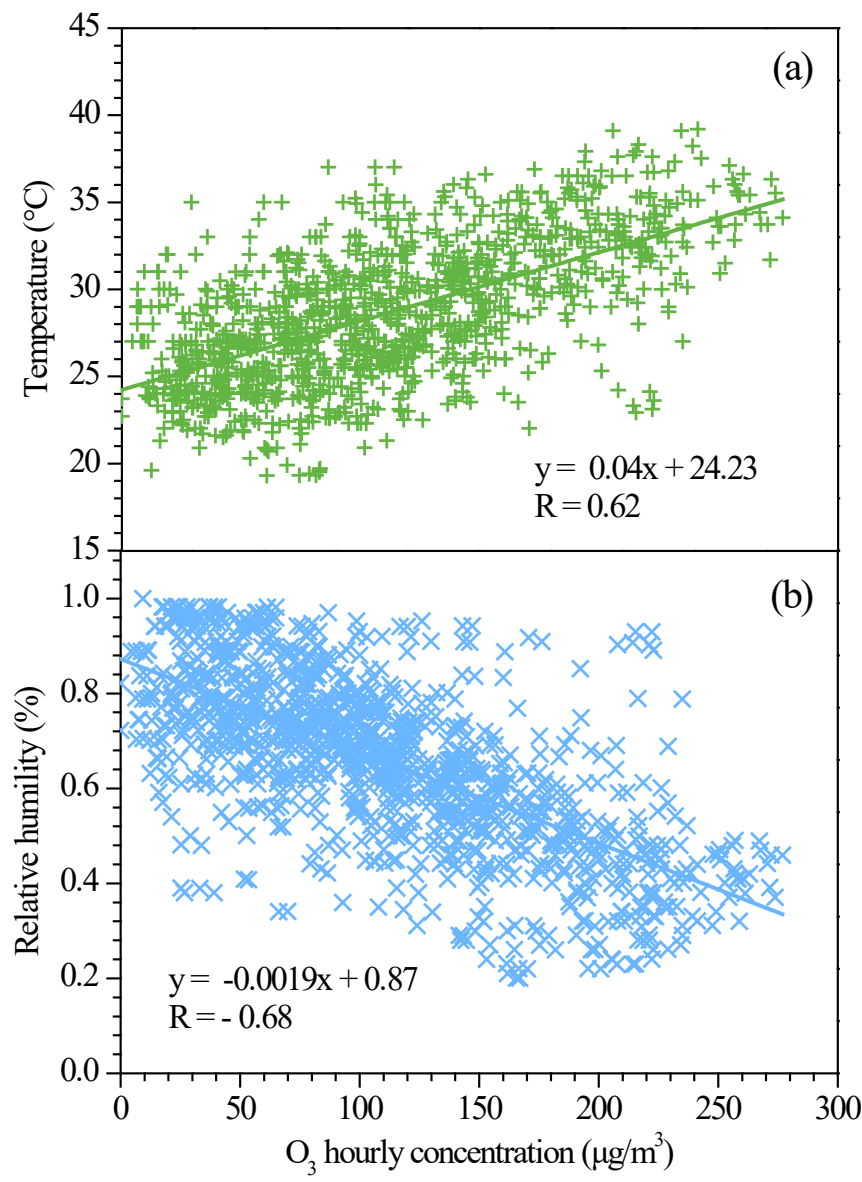

Fig. 6. Correlations between the $\mathrm{O}_{3}$ concentration and (a) temperature or (b) relative humidity in Jinan during summer 2013-2019. 


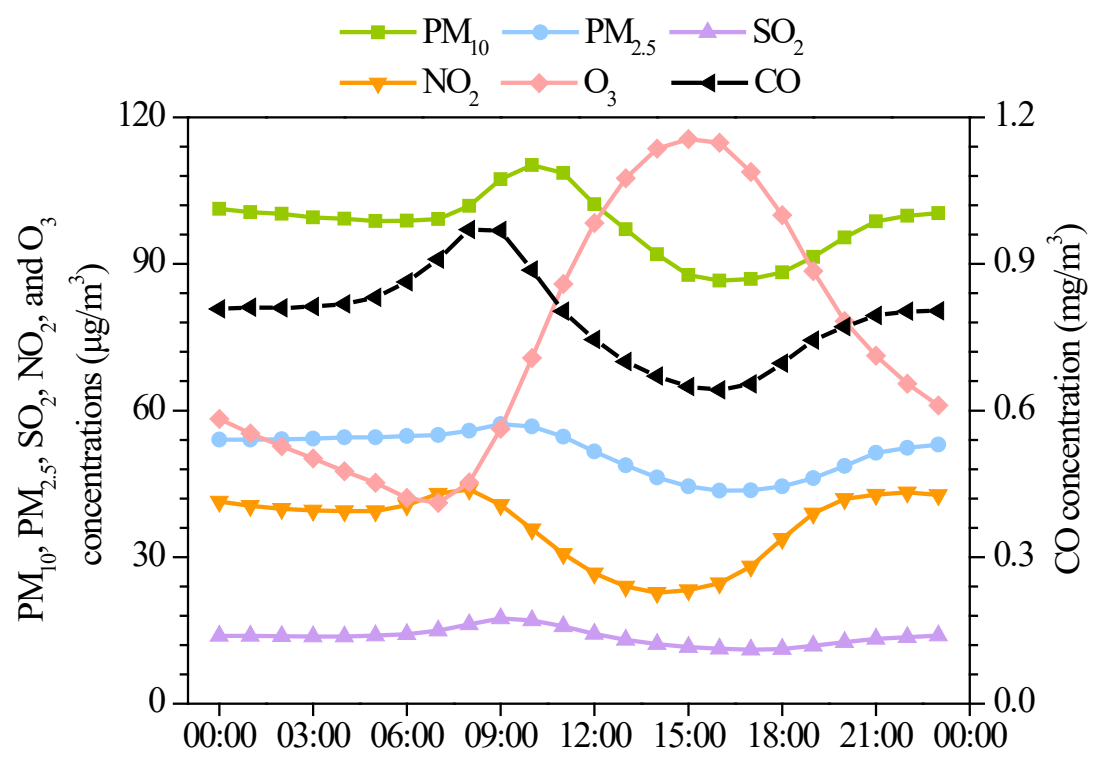

Fig. 7. Diurnal variations in the air pollutant concentrations of Shandong Province during 2019. The variations of the pollutant concentrations in 2013-2017 can be found in Fig. S3. The concentrations are calculated based on the monitoring stations covering 16 cities of Shandong Province.

The diurnal variations in the $\mathrm{PM}_{2.5} / \mathrm{PM}_{10}$ concentration ratio exhibited a trimodal distribution, with peaks at 00:00, from 06:00 to 07:00, and from 13:00 to 14:00, and minimum values from 01:00 to $02: 00,12: 00$ to 13:00, and 17:00 to 19:00 during 2013-2019 (Fig. S4). The higher ratios at the first two peaks were consistent with the diurnal variations in the particle concentrations, while the third peak (13:00-14:00) was contrary to the increasing concentration variation. Although the meteorological conditions were conducive to pollutant diffusion during the third peak, atmospheric oxidation was enhanced by the increases in solar radiation and the $\mathrm{O}_{3}$ concentration (Fig. 7). As the dominant contributor to $\mathrm{PM}_{2.5}$, the formation rate of secondary particles is accelerated by the photochemical and catalytic oxidation reactions of gaseous precursors (such as $\mathrm{SO}_{2}, \mathrm{NO}_{x}$, $\mathrm{NH}_{3}$, and VOCs; Wang et al., 2017a, b), leading to a high $\mathrm{PM}_{2.5} / \mathrm{PM}_{10}$ ratio.

The diurnal variation of the $\mathrm{O}_{3}$ concentration exhibited a typical unimodal distribution, with the peak value at 15:00 and minimum value at 07:00. The higher value of the $\mathrm{O}_{3}$ concentration was mainly due to the photochemical oxidation reactions in the presence of intense solar radiation, which was consistent with the decreases in the contents of precursors, such as $\mathrm{NO}_{2}$ and CO (Ordonez et al., 2005; Yin et al., 2019).

\subsection{Contribution of Meteorological Changes to Air Pollutant Concentration Reductions}

Taking 2013 as the baseline, the inter-annual meteorological changes contributed 3.4-18.6\% to the concentration reductions of six criteria pollutants in Shandong Province during 2015-2019 (Fig. 8). The concentration reductions due to meteorological improvement were much lower than the observed reductions in 2013-2019 ranging from 26.8-80.1\%, indicating that emissions reduction was the dominant factor in the improvement in air quality during this period. The meteorological conditions had little impact on the changes in the $\mathrm{O}_{3}$ concentrations, indicating that synergistic control of $\mathrm{NO}_{x}$ and VOCs was critical to mitigating $\mathrm{O}_{3}$ pollution (Fig. 8). Lu et al. (2019) also reported that more stringent emission control measures were necessary to reduce surface $\mathrm{O}_{3}$ pollution over China, particularly in years with unfavorable meteorological conditions. Overall, the contributions of inter-annual meteorological changes to concentration reductions of five criteria pollutants were similar in 2015 and 2017, with values of 7.9-18.6\% and 7.6-15.9\%, respectively, and higher than that in 2019 (3.4-15.7\%). This indicates that the synoptic circumstances in 2015-2017 were similar, and more effort should be devoted to reducing emissions from anthropogenic sources to improve air quality, as the meteorological conditions in 2019 were less conducive to pollutant diffusion than those in 2015-2017. The results also indicated that the 

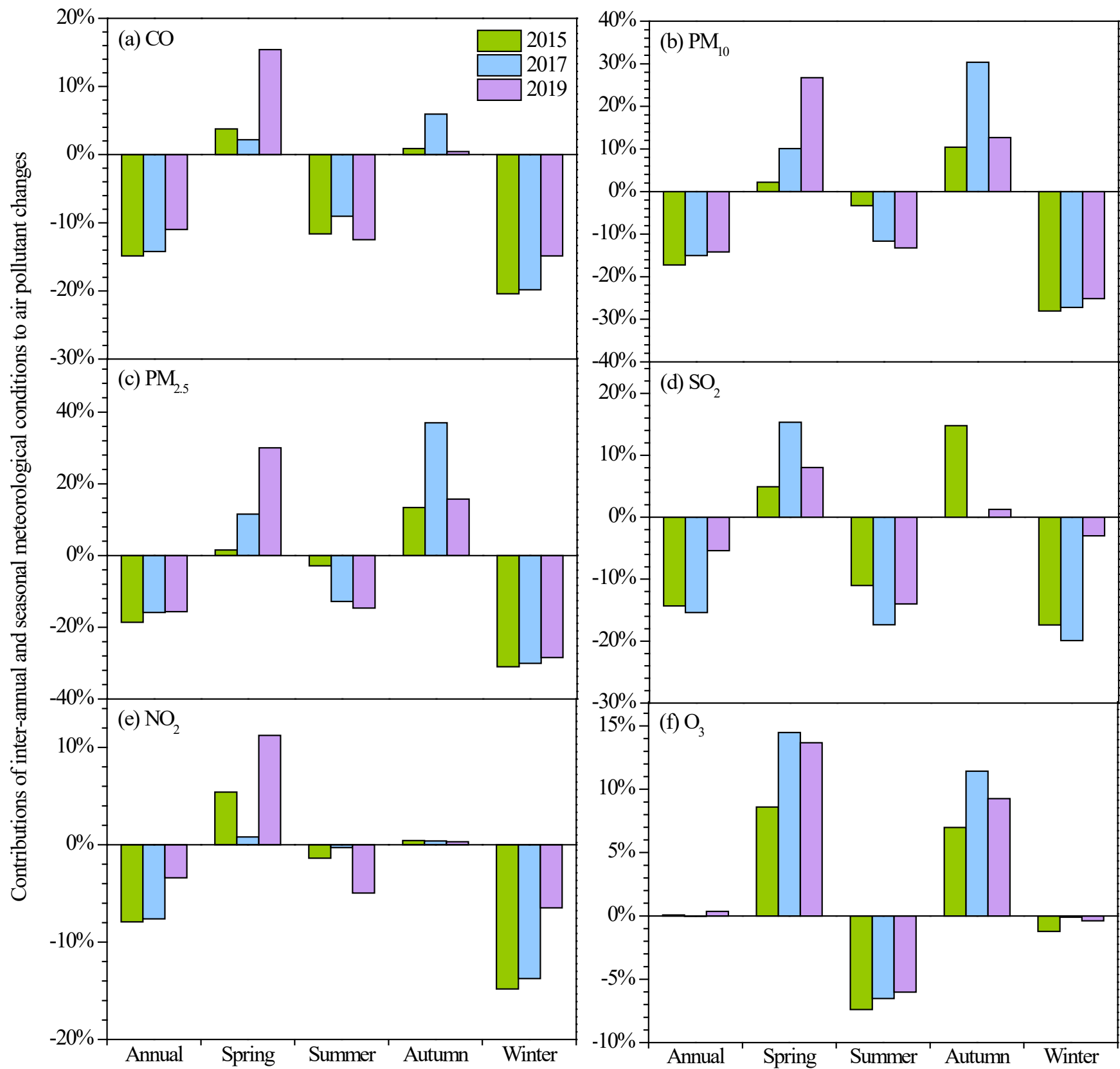

Fig. 8. The contributions of inter-annual and seasonal meteorological changes to air pollutant concentration reductions. This figure presents the relative changes (\%) in the annual and seasonal average air pollutant concentrations in 2015-2019, taking 2013 as the baseline, using the WRF/Chem model. Negative values indicate that the meteorological conditions are conducive to the reduction of air pollutant concentrations in 2015-2019.

meteorological conditions in 2015-2019 were more favorable for reducing $\mathrm{PM}_{2.5}$, with a reduction of $15.7-18.6 \%$, followed by $\mathrm{PM}_{10}$ (14.2-17.2\%), CO (11.0-14.9\%), SO 2 (5.4-15.4\%), and $\mathrm{NO}_{2}$ (3.47.9\%).

Although the contribution of meteorological conditions to the changes of the six criteria pollutants in Shandong Province has not been reported before, several studies have evaluated this contribution in China and key regions, and their results can be compared to those obtained here. Table 3 summarizes the studies that have evaluated the contributions of inter-annual meteorological changes to $\mathrm{PM}_{2.5}$ reduction. Similar to this study, meteorological variations also reduced the $\mathrm{PM}_{2.5}$ concentrations in China ( 9-12\%), Beijing-Tianjin-Hebei ( 5-16\%), the Yangtze River Delta $(\sim 13 \%)$, and Beijing $(\sim 20 \%)$ during different periods, and also played almost equally important roles in reducing air pollution in Beijing during the Asia-Pacific Economic Cooperation 
Table 3. Contribution of meteorological changes to $\mathrm{PM}_{2.5}$ reductions in other studies.

\begin{tabular}{llll}
\hline Study area & Study period & Contribution & Literature \\
\hline China & $2013-2017$ & $9 \%$ & Zhang et al. (2019a) \\
China & $2013-2018$ & $12 \%$ & Zhai et al. (2019) \\
BTH & $2014-2017$ & $9 \%$ & Dong et al. (2020) \\
BTH & $2013-2017$ & $16 \%$ & Zhang et al. (2019a) \\
BTH & $2013-2017$ & $5 \%$ & Zhang et al. (2019b) \\
YRD & $2013-2017$ & $13 \%$ & Chen et al. (2019) \\
Beijing & $2013-2017$ & $20 \%$ & Wang et al. (2017b) \\
Beijing & APEC 2014 & $30 \%$ & \\
Beijing & Parade 2015 & $33 \%$ & \\
\hline
\end{tabular}

BTH: Beijing-Tianjin-Hebei; YRD: Yangtze River Delta; APEC: Asia-Pacific Economic Cooperation; Parade: Grand Military Parade.

in 2014 ( 30\%) and Grand Military Parade in 2015 ( 33\%). This further demonstrates that the contribution of meteorological changes to air pollutant concentration reductions may be influenced by the geographical location, topography, and local climate, indicating the importance of this study in Shandong Province for developing new policies.

The contributions of meteorological changes to the concentration reductions of the six criteria pollutants exhibited clear seasonal variation characteristics. The meteorological conditions were favorable for air pollutant diffusion in summer and winter, and accumulation in spring and autumn during 2015-2019. Overall, during winter, the contribution of the meteorological changes to the pollutant concentration reductions was larger, with a reduction of $6.5-31.0 \%$, excluding $\mathrm{SO}_{2}$ in 2019 and $\mathrm{O}_{3}$. Zhang et al. (2019b) also found that the meteorological factors played a more important role in the decrease of $\mathrm{PM}_{2.5}$ during winter 2017 in the Beijing-Tianjin-Hebei and Yangtze River Delta regions, as the meteorological conditions improved the reductions in $\mathrm{PM}_{2.5}$ by $20 \%$ and $30 \%$ in the two regions, respectively. Note that the meteorological conditions increased the $\mathrm{PM}_{10}$ and $\mathrm{PM}_{2.5}$ concentrations in autumn 2017 by $30.4 \%$ and $37.0 \%$, respectively. Therefore, more attention should be paid to avoid heavily polluted days in autumn and winter due to the large volume of anthropogenic emissions.

\section{CONCLUSIONS}

This study analyzed the trends in concentration for six criteria pollutants from 2013 till 2019 in Shandong Province and quantified the effects of inter-annual and seasonal meteorological changes. Whereas the levels of five of the species decreased by $26.8-80.1 \%$ over this period, with the maximum and minimum annual values occurring during winter and summer, respectively, that of $\mathrm{O}_{3}$ increased, with the inverse seasonal pattern. Additionally, we observed typical bimodal distributions for the diurnal concentrations of the first five pollutants but a typical unimodal distribution for the $\mathrm{O}_{3}$ and a trimodal distribution for the diurnal $\mathrm{PM}_{2.5} / \mathrm{PM}_{10}$ concentration ratios.

Further investigation revealed that inter-annual differences in the weather conditions from 2015 till 2019 decreased the levels of the five criteria pollutants by merely 3.4-18.6\% (compared to the data from 2013) and produced even less of an effect on the $\mathrm{O}_{3}$, indicating that emission control measures were primarily responsible for the enhancement in air quality between 2013 and 2019. However, seasonal meteorological factors, which favored diffusion during summer and winter but accumulation during spring and autumn, played a larger role in the short term for all six species. Therefore, to consistently improve the air quality, more effort must be devoted to reducing emissions from anthropogenic sources, especially during spring and autumn.

\section{ACKNOWLEDGMENTS}

This work was supported by the National Science Foundation of China (21806086), the opening project of Shanghai Key Lab for Urban Ecological Processes and Eco-Restoration (SHUES2020A02), and the Fundamental Research Funds for the Central Universities (20CX06008A). 


\section{SUPPLEMENTARY MATERIAL}

Supplementary data associated with this article can be found in the online version at https://doi.org/10.4209/aaqr.200545

\section{REFERENCES}

Chen, D., Wang, X., Nelson, P., Li, Y., Zhao, N., Zhao, Y., Lang, J., Zhou, Y., Guo, X. (2017). Ship emission inventory and its impact on the $\mathrm{PM}_{2.5}$ air pollution in Qingdao Port, North China. Atmos Environ. 166, 351-361. https://doi.org/10.1016/j.atmosenv.2017.07.021

Chen, D., Zhao, N., Lang, L., Zhou, Y., Wang, X., Li, Y., Zhao, Y., Guo, X. (2018). Contribution of ship emissions to the concentration of $\mathrm{PM}_{2.5}$ : A comprehensive study using AIS data and WRF/Chem model in Bohai Rim Region, China. Sci. Total Environ. 610-611, 1476-1486. https://doi.org/10. 1016/j.scitotenv.2017.07.255

Chen, Z.Y., Chen, D.L., Kwan, M.P., Chen, B., Gao, B.B., Zhuang, Y., Li, R.Y., Xu, B. (2019). The control of anthropogenic emissions contributed to $80 \%$ of the decrease in $\mathrm{PM}_{2.5}$ concentrations in Beijing from 2013 to 2017. Atmos. Chem. Phys. 19, 13519-13533. https://doi.org/10.5194/a cp-19-13519-2019

Chow, J.C., Watson, J.G., Lowenthal, D.H., Solomon, P.A., Magliano, K.L., Ziman, S.D., Richards, L.W. (1993). PM 10 and PM 2.5 compositions in California San Joaquin valley. Aerosol Sci. Technol. 18, 105-128. https://doi.org/10.1080/02786829308959588

Department of Ecological Environment of Shandong Province (DEE) (2018). Shandong Province operation plan for winning the blue-sky defense warfare and the phase iii action plan of air pollution prevention and control plan 2013-2020 (in Chinese). http://www.sdein.gov.cn/dtxx/ hbyw/201808/t20180808_1444314.html (accessed 8 August 2018).

Dong, Z., Wang, S., Xing, J., Chang, X., Ding, D., Zheng, H. (2020). Regional transport in BeijingTianjin-Hebei region and its changes during 2014-2017: The impacts of meteorology and emission reduction. Sci. Total Environ. 737, 139792. https://doi.org/10.1016/j.scitotenv.2020.139792

Emery, C., Tai, E., Yarwood, G. (2001). Enhanced meteorological modeling and performance evaluation for two texas episodes. Report to the Texas Natural Resources Conservation Commission. p.b.E., Internatioanl Corp, Novato, CA

Emery, C., Liu, Z., Russell, A., Odman, M., Yarwood, G., Kumar, N. (2017). Recommendations on statistics and benchmarks to assess photochemical model performance. J. Air Waste Manage. Assoc. 67, 582-598. https://doi.org/10.1080/10962247.2016.1265027

Fang, T., Zhu, Y., Jang, J., Wang, S., Xing, J., Chiang, P., Fan, S., You, Z., Li, J. (2020). Real-time source contribution analysis of ambient ozone using an enhanced meta-modeling approach over the Pearl River Delta Region of China. J. Environ. Manage. 268, 110650. https://doi.org/10. 1016/j.jenvman.2020.110650

Geng, G.N., Xiao, Q.Y., Zheng, Y.X., Tong, D., Zhang, Y.X., Zhang, X.Y., Zhang, Q., He, K.B., Liu, Y. (2019). Impact of China's air pollution prevention and control action plan on $\mathrm{PM}_{2.5}$ chemical composition over eastern China. Sci. China Earth Sci. 62, 1872-1884. https://doi.org/10.1007/s 11430-018-9353-x

Hong, C.P., Zhang, Q., Zhang, Y., Davis, S.J., Tong, D., Zheng, Y.X., Liu, Z., Guan, D.B., He, K.B., Schellnhuber, H.J. (2019). Impacts of climate change on future air quality and human health in China. PNAS 116, 17193-17200. https://doi.org/10.1073/pnas.1812881116

Hu, J., Chen, J., Ying, Q., Zhang, H. (2016). One-year simulation of ozone and particulate matter in China using WRF/CMAQ modeling system. Atmos. Chem. Phys. 16, 10333-10350. https://doi.org/10.5194/acp-16-10333-2016

Jeon, W., Lee, S., Lee, H., Park, C., Kim, D., Park, S. (2014). A study on high ozone formation mechanism associated with change of $\mathrm{NO}_{x} / \mathrm{VOCs}$ ratio at a rural area in the Korean Peninsula. Atmos Environ. 89, 10-21. https://doi.org/10.1016/j.atmosenv.2014.02.005

Kong, L., Feng, M., Liu, Y., Zhang, Y., Zhang, C., Li, C., Qu, Y., An, J., Liu, X., Tan, Q., Cheng, N., Deng, Y., Zhai, R., Wang, Z. (2020). Elucidating the pollution characteristics of nitrate, sulfate and ammonium in $\mathrm{PM}_{2.5}$ in Chengdu, southwest China, based on 3-year measurements. Atmos. Chem. Phys. 20, 11181-11199. https://doi.org/10.5194/acp-20-11181-2020 
Kuerban, M., Waili, Y., Fan, F., Liu, Y., Qin, W., Dore, A., Peng, J., Xu, W., Zhang, F. (2020). Spatiotemporal patterns of air pollution in China from 2015 to 2018 and implications for health risks. Environ Pollut. 258, 113659. https:/doi.org/10.1016/j.envpol.2019.113659

Lang, J.L., Zhang, Y.Y., Zhou, Y., Cheng, S.Y., Chen, D.S., Guo, X.R., Chen, S., Li, X.X., Xing, X.F., Wang, H.Y. (2017). Trends of $\mathrm{PM}_{2.5}$ and chemical composition in Beijing, 2000-2015. Aerosol Air Qual. Res. 17, 412-425. https://doi.org/10.4209/aaqr.2016.07.0307

Li, B., Zhou, S., Wang, T., Zhou, Y., Ge, L., Liao, H. (2020a). Spatio-temporal distribution and influencing factors of atmospheric polycyclic aromatic hydrocarbons in the Yangtze River Delta. J. Cleaner Prod. 267, 122049. https://doi.org/10.1016/j.jclepro.2020.122049

Li, R., Mei, X., Chen, L.F., Wang, L.L., Wang, Z.F., Jiang, Y.Y. (2020b). Long-term (2005-2017) view of atmospheric pollutants in central China using multiple satellite observations. Remote Sens. 12, 1041. https://doi:10.3390/rs12061041

Li, S., Lang, J., Zhou, Y., Liang, X., Chen, D., Wei, P. (2019). Trends in ammonia emissions from light-duty gasoline vehicles in China, 1999-2017. Sci. Total Environ. 700, 134359. https://doi.org/10.1016/j.scitotenv.2019.134359

Liu, F., Zhang, Q., Tong, D., Zheng, B., Li, M., Huo, H., He, K. (2015). High-resolution inventory of technologies, activities, and emissions of coal-fired power plants in China from 1990 to 2010. Atmos. Chem. Phys. 15, 18787-18837. https://doi.org/10.5194/acp-15-13299-2015

Liu, F., Beirle, S., Zhang, Q., Van, D.A.R.J., Zheng, B., Tong, D., He, K. (2017). NO emission trends over Chinese cities estimated from OMI observations during 2005 to 2015. Atmos. Chem. Phys. 17, 9261-9275. https://doi.org/10.5194/acp-17-9261-2017

Lu, X., Zhang, L., Chen, Y.F., Zhou, M., Zheng, B., Li, K., Liu, Y.M., Lin, J.T., Fu, T.M., Zhang, Q. (2019). Exploring 2016-2017 surface ozone pollution over China: source contributions and meteorological influences. Atmos. Chem. Phys. 19, 8339-8361. https://doi.org/10.5194/acp19-8339-2019

Lv, Z., Wei, W., Cheng, S.Y., Han, X.Y., Wang, X.Q. (2020). Meteorological characteristics within boundary layer and its influence on $\mathrm{PM}_{2.5}$ pollution in six cities of North China based on WRFChem. Atmos Environ. 228, 117417. https://doi.org/10.1016/j.atmosenv.2020.117417

Ministry of Ecology and Environment of the People's Republic of China (MEE) (2018). Three-year action plan to win the blue-sky defense war (in Chinese). http://www.mee.gov.cn/ywgz/fgbz/ gz/201807/t20180705_446146.shtml (accessed 4 July 2018).

Ministry of Ecology and Environment of the People's Republic of China (MEE) (2020). Minister of ministry of ecology and environment talks about going all out to fight the battle of pollution prevention (in Chinese). http://www.mee.gov.cn/ywdt/hjywnews/202001/t20200122_76085 8.shtml (accessed 19 January 2020).

Ordonez, C., Mathis, H., Furger, M., Henne, S., Huglin, C., Staehelin, J., Prevot, A.S.H. (2005). Changes of daily surface ozone maxima in Switzerland in all seasons from 1992 to 2002 and discussion of summer 2003. Atmos. Chem. Phys. 5, 1187-1203. https://doi.org/10.5194/acp5-1187-2005

Qiu, X. (2017). The Characteristics of ozone pollution and its nonlinear response to precursor emissions in Huhhot-Baotou-Erdos region (in Chinese). PhD thesis, Tsinghua University, Beijing, China.

Shen, Y., Zhang, L.P., Fang, X., Ji, H.Y., Li, X., Zhao, Z.W. (2018). Spatiotemporal patterns of recent $\mathrm{PM}_{2.5}$ concentrations over typical urban agglomerations in China. Sci. Total Environ. 655, 1326. https://doi.org/10.1016/j.scitotenv.2018.11.105

Squires, F.A., Nemitz, E., Langford, B., Wild, O., Drysdale, W.S., Acton, W.J.F., Fu, P., Grimmond, C.S.B., Hamilton, J.F., Hewitt, C.N., Hollaway, M., Kotthaus, S., Lee, J., Metzger, S., PinginthaDurden, N., Shaw, M., Vaughan, A.R., Wang, X., Wu, R., Zhang, Q., et al. (2020). Measurements of traffic-dominated pollutant emissions in a Chinese megacity. Atmos. Chem. Phys. 20, 87378761. https://doi.org/10.5194/acp-20-8737-2020

Sun, L., Xue, L., Wang, Y., Li, L., Lin, J., Ni, R., Yan, Y., Chen, L., Li, J., Zhang, Q., Wang, W. (2019). Impacts of meteorology and emissions on summertime surface ozone increases over central eastern China between 2003 and 2015. Atmos. Chem. Phys. 19, 1455-1469. https://doi.org/1 0.5194/acp-19-1455-2019

Tang, G., Li, X., Wang, Y., Xin, J., Ren, X. (2009). Surface ozone trend details and interpretations in Beijing, 2001-2006. Atmos. Chem. Phys. 9, 8813-8823. https://doi.org/10.5194/acp-9-8813-2009 
Tie, X., Geng, F., Guenther, A., Cao, J. (2013). Megacity impacts on regional ozone formation: observation and WRF-Chem modeling for the MIRAGE-Shanghai field campaign. Atmos. Chem. Phys. 13, 5655-5669. https://doi.org/10.5194/acp-13-5655-2013

Tong, D., Zhang, Q., Davis, S. J., Liu, F., Zheng, B., Geng, G., Xue, T., Li, M., Hong, C., Lu, Z., Street, G., Guan, D., He, K. (2018). Targeted emission reductions from global super-polluting power plant units. Nat. Sustainability 1, 59-68. https://doi.org/10.1038/s41893-017-0003-y

United States Environmental Protection Agency (U.S. EPA) (2007). Guidance on the use of models and other analyses for demonstrating attainment of air quality goals for ozone, $\mathrm{PM}_{2.5}$, and regional haze. U.S. Environmental Protection Agency Office of Air Quality Planning and Standards Air Quality Analysis Division Air Quality Modeling Group Research Triangle Park, NC.

Vu, T.V., Shi, Z.B., Cheng, J., Zhang, Q., He, K.B., Wang, S.X., Harrison, R.M. (2019). Assessing the impact of clean air action on air quality trends in Beijing using a machine learning technique. Atmos. Chem. Phys. 19, 11303-11314. https://doi.org/10.5194/acp-19-11303-2019

Wang, G., Cheng, S., Li, J., Lang, J., Wen, W., Yang, X., Tian, L. (2015). Source apportionment and seasonal variation of $\mathrm{PM}_{2.5}$ carbonaceous aerosol in the Beijing-Tianjin-Hebei Region of China. Environ Monit Assess 187, 143. https://doi.org/10.1007/s10661-015-4288-x

Wang, G., Cheng, S., Lang, J., Yang, X., Wang, X., Chen, G., Liu, X., Zhang, H. (2017a). Characteristics of $\mathrm{PM}_{2.5}$ and assessing effects of emission-reduction measures in the heavy polluted city of Shijiazhuang, before, during, and after the ceremonial parade 2015. Aerosol Air Qual. Res. 17, 499-512. https://doi.org/10.4209/aaqr.2016.05.0181

Wang, G., Cheng, S., Wei, W., Yang, X., Wang, X., Jia, J., Lang, J.L., Lv, Z. (2017b). Characteristics and emission-reduction measures evaluation of $\mathrm{PM}_{2.5}$ during the two major events: APEC and Parade. Sci. Total Environ. 595, 81-92. https://doi.org/10.1016/j.scitotenv.2017.03.231

Wang, G., Deng, J., Zhang, Y., Li, Y., Ma, Z., Hao, J., Jiang, J. (2020a). Evaluating airborne condensable particulate matter measurement methods in typical stationary sources in China. Environ. Sci. Technol. 54, 1363-1371. https://doi.org/10.1021/acs.est.9b05282

Wang, G., Deng, J., Zhang, Y., Zhang, Q., Duan, L., Hao, J., Jiang, J. (2020b). Air pollutant emissions from coal-fired power plants in China over the past two decades. Sci. Total Environ. 741, 140326. https://doi.org/10.1016/j.scitotenv.2020.140326

Wang, M., Chen, W., Zhang, L., Qin, W., Zhang, Y., Zhang, X., Xie, X. (2020c). Ozone pollution characteristics and sensitivity analysis using an observation-based model in Nanjing, Yangtze River Delta Region of China. J. Environ. Sci. 93, 13-22. https://doi.org/10.1016/j.jes.2020.02.027

Wang, P.F., Chen, K.Y., Zhu, S.Q., Wang, P., Zhang, H.L. (2020d). Severe air pollution events not avoided by reduced anthropogenic activities during COVID-19 outbreak. Resour. Conserv. Recycl. 158, 104814. https://doi.org/10.1016/j.resconrec.2020.104814

Wang, P.F., Guo, H., Hu, J., Kota, S., Ying, Q., Zhang, H.L. (2019a). Responses of $\mathrm{PM}_{2.5}$ and $\mathrm{O}_{3}$ concentrations to changes of meteorology and emissions in China. Sci. Total Environ. 662, 297306. https://doi.org/10.1016/j.scitotenv.2019.01.227

Wang, P.F., Qiao, X., Zhang, H.L. (2020e). Modeling $\mathrm{PM}_{2.5}$ and $\mathrm{O}_{3}$ with aerosol feedbacks using WRF/Chem over the Sichuan Basin, southwestern China. Chemosphere 254, 126735. https://doi.org/10.1016/j.chemosphere.2020.126735

Wang, Y., Li, W., Gao, W., Liu, Z., Tian, S., Shen, R., Ji, D., Wang, S., Wang, L., Tang, G., Song, T., Cheng, M., Wang, G., Gong, Z., Hao, J., Zhang, Y. (2019b). Trends in particulate matter and its chemical compositions in China from 2013-2017. Sci. China Earth Sci. 62, 1857-187. https://doi.org/10.1007/s11430-018-9373-1

Xie, Y.Z., Liu, Z.R., Wen, T.X., Huang, X.J., Liu, J.Y., Tang, G.Q., Yang, Y., Li, X.R., Shen, R.R., Hu, B., Wang, Y.S. (2019). Characteristics of chemical composition and seasonal variations of $\mathrm{PM}_{2.5}$ in Shijiazhuang, China: Impact of primary emissions and secondary formation. Sci. Total Environ. 677, 215-229. https://doi.org/10.1016/j.scitotenv.2019.04.300

Xing, L., Li, G.H., Pongpiachan, S., Wang, Q.Y., Han, Y.M., Cao, J.J., Tipmanee, d., Palakun, j., Aukkaravittayapun, S., Surapipith, V., Poshyachinda, S. (2020). Quantifying the contributions of local emissions and regional transport to elemental carbon in Thailand. Environ. Pollut. 262, 114272. https://doi.org/10.1016/j.envpol.2020.114272

Xiong, T.Q., Jiang, W., Gao, W.D. (2016). Current status and prediction of major atmospheric emissions from coal-fired power plants in Shandong Province, China. Atmos. Environ. 124, 4652. https://doi.org/10.1016/j.atmosenv.2015.11.002 
Xue, Y., Zhang, S., Zhou, Z., Wang, K., Liu, K., Wang, X., Shi, A., Xu, K., Tian, H. (2019). Spatiotemporal variations of multiple primary air pollutants emissions in Beijing of China, 2006-2015. Atmosphere 10, 494. https://doi.org/10.3390/atmos10090494

Xue, Y.F., Zhang, S.H., Nie, T., Cao, X.Z., Shi, A.J. (2020). Environmental effective assessment of control measures implemented by clean air action plan (2013-2017) in Beijing, China. Atmosphere 11, 189. https://doi.org/10.3390/atmos11020189

Yang, L.F., Luo, H.H., Yuan, Z.B., Zheng, J.Y., Huang, Z.J., Li, C., Lin, X.H., Louie, P.K.K., Chen, D.H. (2019). Quantitative impacts of meteorology and precursor emission changes on the long-term trend of ambient ozone over the Pearl River Delta, China and implications for ozone control strategy. Atmos. Chem. Phys. 19, 12901-12916. https://doi.org/10.5194/acp-19-12901-2019

Yin, X.F., Foy de, B., Wu, K.P., Feng, C., Kang, S.C., Zhang, Q.G. (2019). Gaseous and particulate pollutants in Lhasa, Tibet during 2013-2017: Spatial variability, temporal variations and implications. Environ. Pollut. 253, 68-77. https://doi.org/10.1016/j.envpol.2019.06.113

Yu, S., Yin, S., Zhang, R., Wang, L., Su, F., Zhang, Y., Yang, J. (2020). Spatiotemporal characterization and regional contributions of $\mathrm{O}_{3}$ and $\mathrm{NO}_{2}$ : An investigation of two years of monitoring data in Henan, China. J. Environ. Sci. 90, 29-40. https://doi.org/10.1016/j.jes.2019.10.0121001

Zhai, S.X., Jacob, D.J., Wang, X., Shen, L., Li, K., Zhang, Y.Z., Gui, K., Zhao, T.L., Liao, H. (2019). Fine particulate matter $\left(\mathrm{PM}_{2.5}\right)$ trends in China, 2013-2018: Separating contributions from anthropogenic emissions and meteorology. Atmos. Chem. Phys. 19, 11031-11041. https://doi.org/10.5194/acp-19-11031-2019

Zhang, Q., Zheng, Y., Tong, D., Shao, M., Wang, S., Zhang, Y., Xu, X., Wang, J., He, H., Liu, W., Ding, Y., Lei, Y., Li, J., Wang, Z., Zhang, X., Wang, Y., Cheng, J., Liu, Y., Shi, Q., Yan, L., et al. (2019a). Drivers of improved $\mathrm{PM}_{2.5}$ air quality in China from 2013 to 2017. PNAS 116, 24463-24469. https://doi.org/10.1073/pnas.1907956116

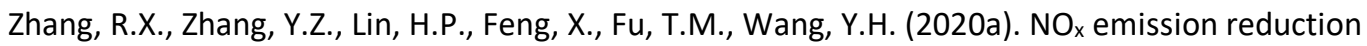
and recovery during COVID-19 in East China. Atmosphere 11, 433. https://doi.org/10.3390/at mos11040433

Zhang, X., Sun, J., Wang, Y., Li, W., Zhang, Q. (2013). Factors contributing to haze and fog in China. Chin. Sci. Bull. 58, 1178-1187. https://doi.org/10.1360/972013-150

Zhang, X.Y., Xu, D.X., Ding, Y.H., Liu, Y.J., Zhang, H.D., Wang, Y.Q., Zhong, J.T. (2019b). The impact of meteorological changes from 2013 to 2017 on $\mathrm{PM}_{2.5}$ mass reduction in key regions in China. Sci. China Earth Sci. 62, 1885-1902. https://doi.org/10.1007/s11430-019-9343-3

Zhang, Y.H., Zhang, S.D., Huang, C.M., Huang, K.M., Gong, Y., Gan, Q. (2014). Diurnal variations of the planetary boundary layer height estimated from intensive radiosonde observations over Yichang, China. Sci. China Technol. Sci. 57, 2172-2176. https://doi.org/10.1007/s11431-0145639-5

Zhang, Y.M., Vu, V.T., Sun, J.Y., He, J.J., Shen, X.J., Lin, W.L., Zhang, X.Y., Zhong, J.T., Gao, W.K., Wang, Y.Q., Fu, T.M., Ma, Y.P., Li, W.J., Shi, Z.B. (2020b). Significant changes in chemistry of fine particles in wintertime Beijing from 2007 to 2017: Impact of clean air actions. Environ. Sci. Technol. 54, 1344-1352. https://doi.org/10.1021/acs.est.9b04678

Zhao, N., Wang, G., Li, G., Lang, J., Zhang, H. (2020). Air pollution episodes during the COVID-19 outbreak in the Beijing-Tianjin-Hebei region of China: An insight into the transport pathways and source distribution. Environ. Pollut. 267, 115617. https://doi.org/10.1016/j.envpol.2020.1 15617

Zheng, B., Tong, D., Li, M., Liu, F., Hong, C., Geng, G., Li, H., Li, X., Peng, L., Qi, J., Yan, L., Zhang, Y., Zhao, H., Zheng, Y., He, K., Zhang, Q. (2018). Trends in China's anthropogenic emissions since 2010 as the consequence of clean air actions. Atmos. Chem. Phys. 18, 14095-14111. https://doi.org/10.5194/acp-18-14095-2018

Zhou, Y., Cheng, S., Chen, D., Lang, J., Wang, G., Xu, T., Wang, X., Yao, S. (2015). Temporal and spatial characteristics of ambient air quality in Beijing, China. Aerosol Air Qual. Res. 15, 18681880. https://doi.org/10.4209/aaqr.2014.11.0306

Zhou, Y., Zi, T., Lang, J., Huang, D., Wei, P., Chen, D., Cheng, S. (2020). Impact of rural residential coal combustion on air pollution in Shandong, China. Chemosphere 260, 127517. https://doi.org/10.1016/j.chemosphere.2020.127517

Zou, Y., Wang, Y., Zhang, Y., Koo, J. (2017). Arctic sea ice, Eurasia snow, and extreme winter haze in China. Sci. Adv. 3, e1602751. https://doi.org/10.1126/sciadv.1602751 